School, where Royal Exhibitioners and other free students are admitted without payment; where the teacher has the first claim, and where he can attend any single course for a nominal fee. Now every town of importance in the country should associate itself with the Government in this attempt, and should have one, at least, of its citizens always in training there, so that the scientific instruction in that town, whether primary, secondary, or tertiary, should always be at its highest level. On the other side of the road, too, at South Kensington, is rapidly rising another institution where we may hope the teachers of our technical instruction will receive an equally careful training. So that you see, to bring what 1 have to say to a conclusion, that though we are late in the day, though many people have not yet made up their minds as to what is best to be done-and I acknowledge that the question is hedged in with difficulties on all sidesthere is an easy solution of the difficulty based on the experience of other countries, which is at the same time an act of simple justice; that this solution requires no dislocation if we adopt it, but simply a natural growth of our existing means, and that al the newest developments of our educational machinery will all fall naturally into place.

\section{THE TRANSIT OF VENUS}

The Observations at the Cape

THE long looked-forward-to transit of Venus occurred yesterday afternoon, causing, we may be sure, a flutter of excitement amongst astronomers throughout the whole of the world. To some the special duty was entrusted of carefully noting everything connected with the ingress of this familiar planet, and after they had concluded their labours at the setting of the sun, it fell to astronomers in other portions of the globe to pay equally minute attention to the planet's egress. By and bye we may expect columns of thoughtfully worked-out details in connection with this peculiar and interesting astronomical event, all of which will tend to still further solve the problem of the exact distance of the sun from the earth. We need not remind our readers that herein consists the whole scientific value of the transit. When crossing the sun's disc the planet is at its nearest distance from the eartb-estimated at about 25,000,000 miles-and through the peculiar facilities thus afforded of directly measuring its parallax, observers are enabled to calculate the parallax of the sun, which to astronomers is a matter of very considerable importance. The credit of the sugrestion of this particular method of calculation is due to Dr. Halley, and it is still popu. larly held to be the best for the purpose. But accompanying the rapid strides astronomic science has taken in its development since the days of Halley, instrumental means have been invented and accepted by modern astronomers, which appear to afford methods, perhaps even more exact, of arriving at the desired result. For all this, however, the transit of Venus retains a powerful hold upon the popular mind, and, indeed, upon the minds of many astronomers, as the best method. There is, too, one specially strong argument why a particular interest should be taken in this planet's transit. No one who witnessed the phenomenon yesterday will live to see it, again-unless, indeed, he fairly outrivals old Parr and other gentlemen famed for longevity. Occurring as these transits do at the unequal but regular recurring intervals of $8, \mathbf{1 2 2}, 8$, and 105 years, no one could well expect to see more than two in a lifetime. The last took place in I874, while the next will occur in December, 2007. It need, therefore, be no longer surprising why, both popularly and scientifically, the event is regarded as one of such special in terest, and why the most eminent scientific observers are selected to note everything that takes place.

Before proceeding to refer to the observations which were taken yesterday at the Royal Observatory we may mention that, acting under the advice of the Astronomer-Royal of the Cape of Good Hope (Dr. Gill), the British Transit of Venus Committee decided upon establishing stations at Aberdeen Road and Montagu Rond as auxiliary places of observation to the principal station here at the Observatory itself. And before proceeding further it may be added that Natal has come forward very pluckily in this matter, exhibiting an amount of interest in astronomic science which does great credit to that colony. Mr. Escombe himself contributed a sum of between $400 \%$. and 500 . for the purpose of providing a proper tele cope; while two merchants subscribed $50 l$. each, the Corporation of Durban giving $300 l$, and the Natal Government voting $500 l$. towards ${ }^{x}$ From the Cape Times, December 7, 1882. founding an observatory for the colony, and the defraying of expenses connected with taking observations of the present transit. As a pleasant sequel to this, we are glad to learn by telegraph, that Mr. Neison, who was in charge of the party of observation there, most successfully observed the internal contact at Durban, the enterprise of Natal thus meeting with a well-merited reward. As announced by us some time since, South Africa was selected by the Americans as a station for one of their photographic transit of Venus expeditions under the charge of Prof. Newcomb, who has the reputation of being one of the most celebrated of living astronomers. On arrival here Prof. Newcomb, after consultation with the best auth urities as to atmospheric conditions, \&c., finally decided, with the kind consent of the trustees of the Hugruenot Seminary to take his observations from the foot of the gardens of that institution at Wellington. We hope to shortly hear of the entire success of the labours of the party, and perhaps to see some specimens of their photograpbic skill.

At the Observatory itself it need scarcely be said that for some weeks past great preparations had been made for the event. There are few living astronomers who have more carefully studied the subject of the transit of Venus than the present Astronomer-Royal here, Dr. Gill, and few are more thoroughly posted up in all the details of the rare occurrence. In 1874 Dr. Gill was Chief Astronomer to Lord Lindsay's Transit of Venus Expedition to the Mauritius, where he not only took most valuable observations, but evinced a very intimate acquaintance with the entire subject. It was only to be expected, therefore, that in this instance no detail in connection with the arrangements for a proper observation in Cape Colony would be lost sight of by the Astron omer-Royal. The few visitors who received invitations to the Observatory yesterday found Dr. Gill courteous and affable as ever, but wholly absorbed in the important work on hand. "You may go here and go there, look through that glass and have a peep through the other one," were his remarks just before commencing operations, "but whatever you do, please don't speak to me or any of the observers until the internal contact has been made." No injunction not to speak to the "man at the wheel" could have been more respected than this, and from that moment until a couple of hours later Dr. Gill and his assistants became objects of almost reverential awe to those outside the pale of strict astronomic science.

One of the principal instruments employed was a new equa. torial telescope by Grubb of Dublin, made and sent out here specially for the transit of Venus, the old wind tower in which it is now mounted having been prepared as an observatory for its reception. There was also a heliometer which had been used at the last transit by Dr. Gill at the Mauritius, and was afterwards borrowed by him from Lord Lindsay for use on the Isle of Ascension, where he made a determination of the sun's distance from the planet Mars. Subsequently this fine instrument was purchased by Dr. Gill and was brought out here as his private property on his being appointed Astronomer-Royal at the Cape. Another noticeable instrument employed yesterday was the great theodolite intended for the trigonometrical survey of India. The designs of Col. Strange, however, from which it was constructed, were so long in being carried out in manufacture that General Walker, the Director of Survey, decided not to bring it into use, especially as it was somewhat too heavy for service in the field. Upon the application of Dr. Gill, it was lent by the Indian Government, for the purpose of some special researches in which that gentleman was engaged at the time, and it was successfully employed the other day in taking observations of the great comet. The other i astruments included a small equatorial telescope of $3 \frac{1}{8}$ inches aperture, which was used by Mr. Stone on the occasion of the last transit of Venus; an equatorial telescope of 7 inches aperture, which has also been for some time at the Observatory, and a telescope of $2 \frac{1}{2}$ inches aperture belonging to Capt. Jurisch, examiner of diagrams in the Surveyor-General's department. Having mentioned the several instruments, we must go on to state by whom they were used. Dr. Gill himself observed the contact of Venus with the sun's limb, with the new 6 -inch aperture equatorial, a similar observation being taken by Mr. Maclear with the 7.inch equatorial. Dr. Elkin, a scientific friend and guest of the Astronomer-Royal, took observations with the heliometer; Mr. Freeman, with the great theodolite; Mr. Pillans, with the small equatorial ; and Capt. Jurisch with his own equatorial. Several important measures were also taken at the heliometer by Dr. Gill and Dr. Elkin. 
With regard to the weather, which of course was a very important element, the sky was perfectly clear, and altogether suitable for the purpose of observation. There was a light south-east wind blowing, and this prevented the definition being so steady as might have been wished. We are "officially" assured, however, that on the whole the observations made at the Cape of Good Hope may be regarded as perfectly satisfactory, and that they will add considerably towards the solution of the problem of the sun's exact distance from the earth. We have already intimated that at the suggestion of Dr. Gill, other stations than that of the Observatory had been selected. At Aberdeen Road, Mr. Finlay (of comet fame), the first Assistant at the Cape Observatory, and Mr. Pette, third Assistant, were provided with an equatorial of six inches aperture, and the report received last evening by telegraph, was that complete success had attended their labours. Mr. Marth, the well-known astronomer, was detailed at Montagu Road in charge of one of the British Transit of Venus Expeditions, and was provided with a 6-inch aperture equatorial, his assistant, Mr. Stephen, formerly of the Observatory, and now of the Treasury Department, Cape Town, being provided with a $4 \frac{1}{2}$-inch equatorial. In his report last evening, Mr. Marth states that the sky was cloudless, but a heavy dust-storm prevailed during the day. $\mathrm{He}$ reported, however, that the important internal contact was observed satisfactorily both by bimself and Mr. Stephen. A report from Capt. Skead, in conjunction with Mr. Spindler, of Port Elizabetb, states that they also obtained satisfactory observations.

We fear that the courtesy of the General Manager of Telegraphs, Mr. Sivewright, must have been sorely tested by the frequent demand upon his staff for signals for the purpose of determining longitudes, \&c. The telegraphic department, we ought to state, has given the utmost facilities in connection with these operations, and thanks to the co-operation of the General Manager, everything connected with his department was accomplished without a hitch. The transit of Venus expedition will indeed be indebted to $\mathrm{Mr}$. Sivewright for his energy and devotion in their interests. This additional work has necessarily fallen heavily upon the shoulders of the staff at the Observatory. Not only has the normal work of that establi-hment been carried on as diligently as heretofore, but there has been the additional task of taking observations of the great comet, which with other things has told severely upon the endurance of Dr. Gill and his assistants. Judging, though, from what we saw there yesterday, there is no sign of anyone breaking down under the strain of extra work.

The signals for time comparison were sent to the observers engaged in the transit about aine o'clock on Tuesday evening The night is described as having been beautifully clear, aud the occultation of the bright star Spica Virginus was observed in the early morning. Signals were also sent to Mr. Eddie, Graham's Town.

We have thus far briefly sketched the manner in which the observations were taken yesterday-excepting the somewhat primitive methot of smoked glass adopted by a good many of the general public, to whom the transit of Venus was not quite such a matter of exquisite nicety as to such gentlemen as those to whom we have just alluded. From a non-astronomic point of view there was even with the aid of the proper instruments, only to be seen a dark spot crossing the sun, resembling very much a Wimbledon bull's eye. Roughly speaking; the planet made its external contact at five minutes past three o'clock, when through a proper instrument it might have been seen minutely notching into the sun's edge. At twenty-five minutes past the hour-still roughly speaking, for when the calculations are worked out there might be a fractional part of a second one way or the other-the internal contact occurred.

The sun set long before the transit had been completed. It consequently fell to the lot of other astronomers to observe its egress, which of course was as eagerly watched for as had been that of the ingress. The ingress, it might be interesting to mention, was visible in North and South America ; Europe, excepting the west of Russia and the north of Norway and Sweden ; the whole of Africa, Madagascar, Seychelles, and the Mauritius. The egress was visible in North and South America, Australia, New Zealand, and nearly the whole of the South Pacific. This egress will have been completed by about eight o'clock this morning, and then all interested in the subject of Venus may look forward to another 122 years before the interesting occurrence again takes place.

\section{ELECTRIC RAILWAYS ${ }^{1}$}

$\mathrm{WE}^{\mathrm{E}}$ have grown so accustomed to the regular announcement"serious-accident on such and such a railway, several passengers injured" that we have almost come to regard railway accidents as inevitable, just as parents mistakingly think the measles and whooping cough necessary accompaniments of childhood. But speed no more means disaster than a densely crowded city means disease. The first effect of overcrowding is undoubtedly to produce fever and other complaints. If, how: ever, the knowledge and practice of the laws of hygiene increase more rapidly than the population of a town, the death-rate, as we have seen, diminishes, instead of augmenting. And so it is with locomotion; the stage-coach journeys of our ancestors were slow enough for the most staunch conservative, and yet the percentage of the passengers injured on their journeys was far greater than even now with our harum-scarum railway travelling. The number of passengers has increased enormously, but the safety has increased in an even greater rate. If then we can devise methods introducing still greater security, a far larger number of passengers may travel at a far greater speed and with less fear of danger than at present.

Accidents constitute one charge against railway conveyance, but there is another, and that is the cost. Cheap as railway travelling now is, compared with the departed stage-coach locomotion, the price of the tickets is still far too high for railways to fulfil, even in a small degree, one of their most important functions, and that is transporting labourers from parts of the country where labour is scarce, to others where it is abundant and labourers in demand.

But how is a happier state of things to he realised? We cannot expect the railway companies to lower their fares merely to benefit humanity. If, $h$,wever, we can prove to them that the present system of railways is neither the most remunerative to themselves nor the most beneficial to the community at large, we may hope to win the attention of railway directors, whose stock question is, and quite rightly, "Will it pay?"

Those of you who have read the life of Stephenson know what a protracted fight he bad to carry one of his most cherished ideas, and that was the employment of a locomotive engine to draw the train, instead of a stationary engine to pull it with ropes or chains. His adversaries saw the disadvantage of ad ling the weight of the locomotive to the weight of the train, whereas Stephenson was especially struck with the enormous waste of power in the friction of ropes or chains passing over pulleys. [Experiments were then shown proving, first, that the mass of the locomotive necessitated the engine having a greater horsepower to get up the speed of the train quickly as well as a greater horse-power to keep up the speed; secondly, that the friction and wear and tear of ropes, such as were employed on the London and Blackwall Railway, would have been an insuperable hindrance to the development of railways.] From this was deduced that, since in Stephenson's day the only feasible mode of communicating the power of a stationary engine to a moving train was by means of ropes, his decision to adopt the locomotive was perfectly correct at the time it was made.

Attempts have been made to propel trains by blowing them through tubes, or by blowing a piston attached to the train through a tube, but such attempts at pneumatic railways bave nearly all been abandoned. The employment of air compressed into a receiver on the train by fixed pumping engines stationed at various points along the line, and employed to work compressed air engines on the carriages has been effected with considerable success by Col. Beaumont, especially for tram-lines. The weight of the compressed air-engine is, however, still very considerable. Any system of pumping water through a pipe and employing the water to work a hydraulic engine on the train is bardly worth considering, seeing that the mechanical difficulties of keeping up a continuous connection between the moving train and the main through which the water is pumped seem insuperable. Gas-engines worked with ordins ry coal-gas, stored perhaps under pressure, might be employed on the moving train, but the advantage arising from the absence of boiler and coal would be more than compensated for by the fact, that the weight of a gas-engine per horse-power developed is so much greater than that of a steam-engine. None of these systems, then, of dispensing with a locomotive is by any means perfect, and the success of the recent experiments on the electric transmission of

${ }^{3}$ Abstract of a lecture at the Royal Institution by Prof. W. E. Ayrton, F.R.S. 